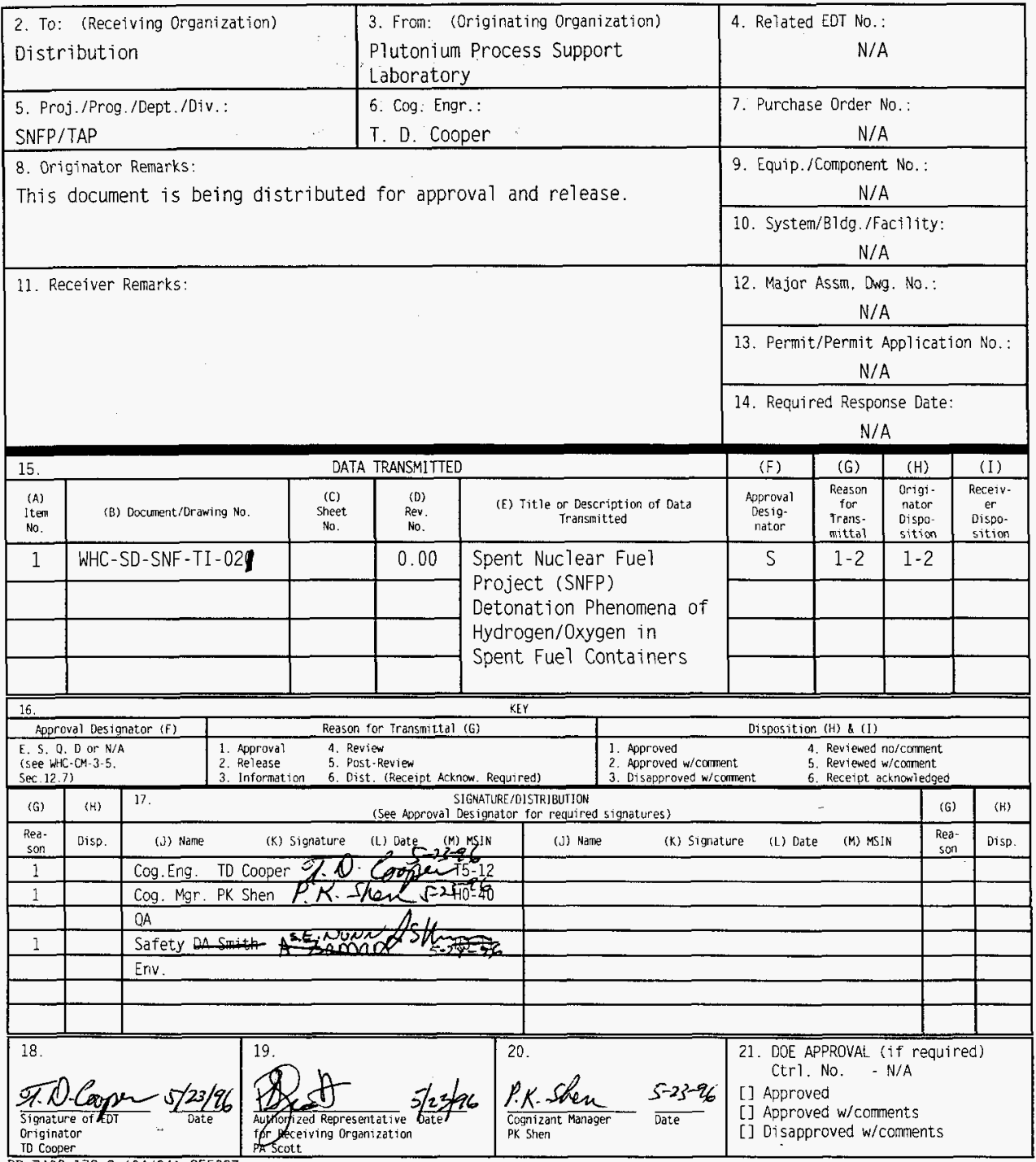




\title{
SNFP Detonation Phenomena of Hydrogen/Oxygen in Spent Fuel Containers
}

\author{
Thurman D. Cooper \\ Westinghouse Hanford Company, Richland, WA 99352 \\ U.S. Department of Energy Contract DE-AC06-87RL10930 \\ EDT/ECN: 616628 \\ Org Code: 15500 15F00 kN \\ B\&R Code: EW3135040 \\ UC: 510 \\ Charge Code: LB040 \\ Total Pages: 3535
}

Key Words: Detonation, Hot Vacuum Conditioning

Abstract: $\quad$ Movement of Spent N Reactor fuels from the Hanford K Basins near the Columbia River to Dry interim storage facility on the Hanford plateau will require repackaging the fuel in the basins into multi canister overpacks (MCOs), drying of the fuel, transporting the contained fuel, hot conditioning, and finally interim storage. Each of these functions will be accomplished while the fuel is contained in the MCOs. Hydrogen and oxygen can be generated within the MCOs by several mechanisms. The principal source of hydrogen and oxygen within the MCOs is residual water from the vacuum drying and hot conditioning operations. This document assesses the detonation phenomena of hydrogen and oxygen in the spent fuel containers.

Several process scenarios have been identified that could generate detonation pressures that exceed the nominal 10 atmosphere design limit of the MCOs. Only 42 grams of radiolized water are required to establish this condition.

TRADEMARK DISCLAIMER. Reference herein to any specific commercial product, process, or service by trade name, trademark, manufacturer, or otherwise, does not necessarily constitute or imply its endorsement, recommendation, or favoring by the United States Government or any agency thereof or its contractors or subcontractors.

Printed in the United States of America. To obtain copies of this document, contact: WHC/BCS Document Control Services, P.O. Box 1970, Mailstop H6-08, Richland WA 99352, Phone (509) 372-2420; Fax (509) 376-4989.
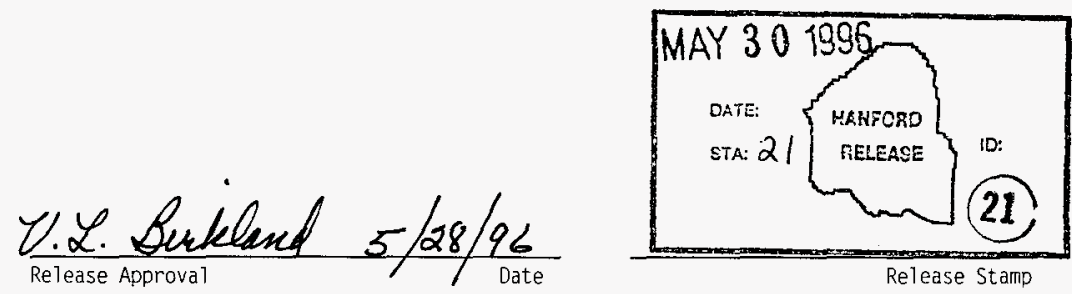

\section{Approved for Public Release}


WHC-SD-SNF-TI-021

Revision 0

This page intentionally left blank. 


\section{CONTENTS}

EXECUTIVE SUMMARY ES-1

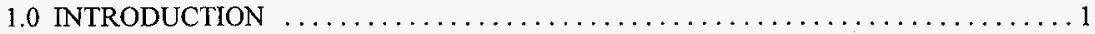

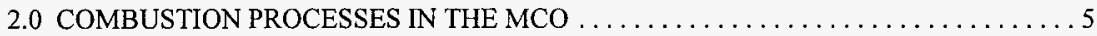

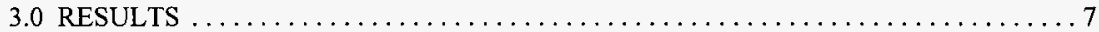

3.1 FULLY FLOODED CONFIGURATION $\ldots \ldots \ldots \ldots \ldots \ldots \ldots \ldots \ldots \ldots \ldots$

3.2 COLD VACUUM DRYING $\ldots \ldots \ldots \ldots \ldots \ldots \ldots \ldots \ldots \ldots \ldots \ldots \ldots \ldots \ldots \ldots \ldots \ldots$

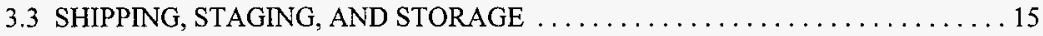

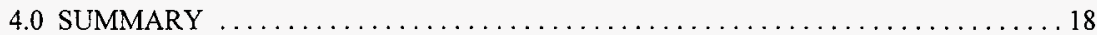

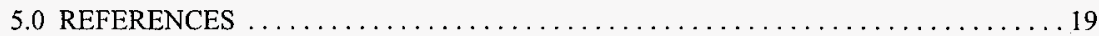

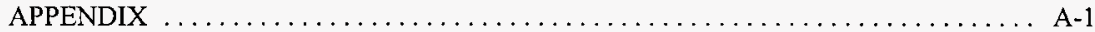




\section{LIST OF TABLES}

1. Detonation Pressure ratios $\left(\mathrm{P}_{\mathrm{P}}\right)$ for the Flooded $\mathrm{MCO} \ldots \ldots \ldots \ldots \ldots \ldots$

2. Detonation Pressure Ratio for Vacuum Side of Pump .................... 11

3. Detonation Pressure Ratios for the Pressure Side of the Pump $\ldots \ldots \ldots \ldots \ldots \ldots \ldots$

4. Detonation Pressure Ratios During Shipping, Staging, \& Storage . . . . . . . . . 15

\section{LIST OF FIGURES}

1. Detonation Pressures in Fully Flooded Configurations $\ldots \ldots \ldots \ldots \ldots \ldots \ldots \ldots \ldots$

2. Detonation Pressures on the Vacuum Side of the Pump . . . . . . . . . . . . . 12

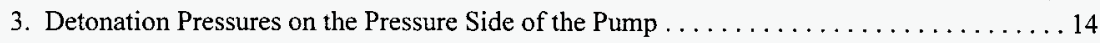

4. Ratio of Detonation Pressures to Ambient Pressures for Shipping, Staging, and Storage . . 16

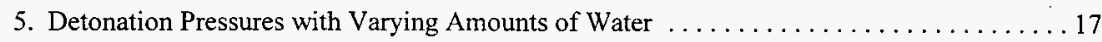


WHC-SD-SNF-TI-021

Revision 0

\section{EXECUTIVE SUMMARY}

The U.S. Department of Energy (DOE) established the Spent Nuclear Fuel Project (SNF Project) to address safety and environmental concerns associated with deteriorating spent nuclear fuel presently stored in the Hanford Site's K Basins. The SNF Project has been tasked by the DOE with moving the spent nuclear fuel from wet storage to contained dry storage in order to reduce operating costs and environmental hazards. The purpose of this document is to address the detonation phenomena of hydrogen and oxygen in the spent fuel containers.

Although hydrogen and oxygen are not initially present in significant quantities in the Multi-Canister Overpack (MCO); they are produced by several mechanisms. MCOs containing damaged fuel elements where uranium fuel and residual water are present will result in corrosion of the uranium. In this aqueous corrosion reaction, oxygen will be consumed generating $\mathrm{UO}_{2}$ and monatomic hydrogen. Any free oxygen would then be gettered by the monatomic hydrogen. Thus for an MCO scenario where sufficient fuel is exposed to water, free hydrogen in an oxygen free atmosphere would be expected. Such an atmosphere (given no external air in-leakage) would have a non-stoichiometric hydrogen oxygen mixture that could not support deflagration or detonation.

Radiolytic decomposition of residual water, though a slower reaction process, produces hydrogen and oxygen in a stoichiometric ratio consistent with detonation or deflagration. It is generally agreed that hydrogen is relatively non-reactive at or near ambient temperatures and would build in concentration in storage over time. Radiolytically produced oxygen is more reactive, and does not always build in concentration. In an MCO with intact fuel assemblies, oxygen is not expected to be depleted significantly by the zirconium cladding or the stainless steel containment materials and is expected to build in concentration. Therefore, the potential for deflagration or detonation of these gases has been explored.

Several process configurations have been identified wherein detonation pressures exceed the nominal 10 atmosphere pressure design limit for the MCOs. Only 42 grams of radiolyzed water are required to establish this condition. Unless the drying or conditioning process can assure that less than 42 grams of residual water are present during sealed staging or storage, a hydrogen or oxygen gettering material should be present in the $\mathrm{MCO}$ to assure that the internal atmosphere will not support deflagration or detonation. An oxygen gettering candidate might be a damaged fuel element. 
WHC-SD-SNF-TI-021

Revision 0

\section{SPENT NUCLEAR FUEL PROJECT DETONATION PHENOMENA OF HYDROGEN/OXYGEN IN SPENT FUEL CONTAINERS}

\subsection{INTRODUCTION}

The Spent Nuclear Fuel Project (SNF Project) is evaluating the concept of transferring spent nuclear fuel from wet pool storage in the K-Basins to dry fuel storage in the Canister Storage Building (CSB). The operational sequence is to lower the MCO into the K-Basin pool, and fill with approximately 270 fuel assemblies arranged in 5 vertical layers.

After loading, the MCO lid will be seal welded and the MCO will be transported to the cold vacuum drying station, where the free water will be drained, and then vacuum dried at $50-70{ }^{\circ} \mathrm{C}$. Next, the MCO will be transported to the CSB and placed in temporary storage in a vented condition until the Hot Conditioning Annex facility is built. This staging period may last from several months to several years.

The hot conditioning process will consist of heating the $\mathrm{MCO}$ to $300{ }^{\circ} \mathrm{C}$ under vacuum to remove waters of hydration and some hydrogen from the uranium hydrides. After hydrogen and water are removed to detection or process limits, the $\mathrm{MCO}$ will be cooled to $150^{\circ} \mathrm{C}$ and treated with oxygen to stabilize all remaining reactive surfaces.

Finally, the MCO will be back-filled with helium or argon and placed in long-term sealed storage (nominally 75 years). During each process step, the potential exists for the production of hydrogen gas. Hydrogen can be produced by radiolysis

$$
\begin{aligned}
& \mathrm{H}_{2} \mathrm{O}+\gamma \rightarrow \mathrm{H} \cdot+\cdot \mathrm{OH} \\
& 2 \mathrm{H} \cdot \rightarrow \mathrm{H}_{2} \\
& 4 \cdot \mathrm{OH} \rightarrow 2 \mathrm{H}_{2} \mathrm{O}+\mathrm{O}_{2}
\end{aligned}
$$

Radiolysis therefore produces hydrogen and oxygen in approximately the correct stoichiometric ratio for an energetic reaction.

Hydrogen can also be created by chemical reactions of water with uranium metal.

$$
2 \mathrm{H}_{2} \mathrm{O}+2 \mathrm{U} \rightarrow \mathrm{UO}_{2}+4 \mathrm{H} \bullet
$$

These hydrogen radicals are powerful oxygen getters so they deplete oxygen according to: 
WHC-SD-SNF-TI-021

Revision 0

$$
4 \mathrm{H} \bullet+\mathrm{O}_{2} \rightarrow 2 \mathrm{H}_{2} \mathrm{O}
$$

After the oxygen has been depleted, hydrogen gas is produced:

$$
4 \mathrm{H} \cdot \rightarrow 2 \mathrm{H}_{2}
$$

It is therefore concluded that chemical reactions between water and uranium result in an MCO atmosphere with excess hydrogen and sufficiently depleted oxygen to pose no explosive hazard. Further mixing of this hydrogen with gaseous oxidizers could, however, recreate an explosive hazard.

This study was not designed to predict the occurrence of an initiating spark or high temperature event that could produce a deflagration. It is nevertheless believed that the fuel assemblies, as they exist in the pool, may contain some concentrations of uranium hydride. Additional hydride will not form in the presence of oxygen; however, more hydride may form whenever the MCO contains water and is oxygen deficient. This hydride may react vigorously if suddenly exposed to oxygen, reaching temperatures in excess of $1800^{\circ} \mathrm{K}$. Thus, combustion of uranium hydride can be added to spark sources due to mechanical or electrical phenomena as potential ignition sources for hydrogen.

Backfilling an MCO with an inert gas such as argon or helium does not eliminate the possibility of a deflagration or detonation. If sufficient oxygen and fuel are mixed with the inert gas in the correct ratios, it is easier to achieve a detonation in a monatomic inert gas medium than in a diatomic gas medium such as nitrogen. Since monatomic gases cannot absorb energy in vibrational modes, their heat capacities are smaller than for diatomic molecules; consequently, they heat more rapidly.

If sufficient oxygen and fuel are available and ignited, will the system transition from deflagration to detonation? Deflagration to detonation transition (DDT) is not a process that can be predicted or modeled from fundamental principles and is therefore approached empirically.

Even empirical DDT data must be evaluated carefully. Because of the many independent variables, differing results have been obtained by various experiments in which these variables are not properly understood or controlled. As a result, any statements made in this report relative to a DDT event should be viewed as advisory and not as a proven fact.

Despite the above disclaimer, it is known that an inert, monatomic gas matrix containing a stoichiometric hydrogen/oxygen mixture in $85 \%$ argon at ambient pressure possesses a detonation cell dimension of 0.85 centimeter. Since the void space within an MCO is 500 liters, with approximately 44 liters in the lid's head space, it is assumed that there is no dimensional restriction against detonations for this case. Thus, give an ignition source and sufficient $\mathrm{O}_{2}$, then detonation within the MCO during sealed storage or staging conditions can be expected. 
The potential for detonation during process vacuum conditioning should be re-examined once process parameters are better defined. If the detonation cell dimensions exceed the available MCO free space, DDT will not occur. The detonation cell dimension is inversely related to the system heat capacity, the gas pressure, and the reaction enthalpy. Based upon these factors, the vacuum process conditions would tend to cause a larger detonation cell. Therefore, it may be possible to show that detonation conditions are not be possible during vacuum conditioning. 
WHC-SD-SNF-TI-021

Revision 0

This page intentionally left blank. 


\subsection{COMBUSTION PROCESSES IN THE MCO}

Deflagration is defined as the simple combustion of hydrogen and oxygen, wherein the combustion process propagates within the gas at less than the speed of sound. Deflagration can release heat and pressurize the MCO. The amount of heat released is determined by the enthalpy of combustion. The pressure is proportional to the rise in absolute temperature resulting from the combustion process.

In contrast, a detonation wave may be initiated by a spark or through deflagration to detonation transition. Within the detonation wave, heating is caused by compression, and is adiabatic. The detonation wave moves faster than the speed of sound and achieves a higher pressure and temperature than that resulting from deflagration.

The equation relating the pressure rise in a detonation wave to the variables of the system was supplied by W. Wilson of Science Applications International Corporation (Wilson 1996):

$$
\pi=2^{*}\left(\gamma_{2-1} / \gamma_{1}-1\right) *\left(\mathrm{Q} / \mathrm{C}_{\mathrm{vl}}{ }^{*} \mathrm{~T}_{\mathrm{l}}\right.
$$

Where:

$$
\gamma=C_{\mathrm{v}} / C_{p}
$$

$Q$ is the system enthalpy, $T_{1}$ refers to the absolute gas temperature at equilibrium, $C_{v}$ is the heat capacity of the system at constant volume, and $C_{p}$ is the heat capacity of the system at constant pressure. The subscripts 2 and 1 refer to the final and initial states of the gas.

This equation is based upon the thermodynamic and fluid mechanical requirements for the propagation of a discontinuous interface between reactants and products in a fluid medium (Landau 1993).

The mixture heat capacities are estimated from quadratic fits (Spencer 1945) to temperature-dependent heat capacities of the individual components. The exothernicity of the reaction $Q$ is taken from the JANAF tables (Chase 1986). Pressures calculated from equation (7) generally agree with experimental measurements within a few percent (Wilson 1996). 
WHC-SD-SNF-TI-021

Revision 0

This page intentionally left blank. 


\subsection{RESULTS}

Two questions are pertinent to this report: Will a deflagration or detonation occur? And, given a deflagration or detonation, what is the maximum pressure exerted on the MCO? Since a detonation provides the highest temperatures and pressures, all subsequent analyses will be focused upon detonation events.

Factors determining whether a detonation is possible include: the molar composition and pressures of the gases, the heat capacity of the gases, the initial temperature of the gases, and the occurrence of an initiating event such as a spark or high temperature.

The theoretical basis for estimating initiation requirements is not well-developed, and its study requires an empirical basis. Three categories of initiations are commonly studied: shock-to detonation transition, jet-to-detonation transition, and deflagration-to-detonation transition. There is an emerging understanding of a connection among the thresholds for each involving the fundamental structure of the detonation front (Fickett 1979 and Lee 1984). It has a threedimensional cellular structure whose characteristic size $\lambda$ is related to initiation phenomena. The critical energy for shock initiation scales as $\lambda^{3}$, while jet initiation requires an orifice diameter of $13 \lambda$. DDT has been shown to occur in hydrogen-air-steam mixtures when the tube diameter reaches the $\lambda$ measured in shock initiated detonations (Ciccarelli 1996) - this is the minimum size for detonation propagation regardless of the initiation mode.

DDT is a complex process not amenable to a priori modeling prediction. Its occurrence depends on local turbulence levels, geometry, wall roughness, etc. It exhibits strong spatial requirements. Ideally, $\lambda$ imposes a minimum size requirement. In other situations, a scaling with $\lambda$ is expected. Thus, $\lambda$ determined from shock-initiated detonations may be taken as equivalent to the requirements for DDT.

Stoichiometric hydrogen air mixtures at 1 atmosphere pressure have an initiation cell size of $1 \mathrm{~cm}$ (Wilson 1996). The cell $\lambda$ rises sharply below $17 \%$ and above $60 \%$ hydrogen at room temperature. The detonation range widens as the ambient temperature is increased. Cell size data in hydrogen-oxygen-argon mixtures have been established over wide ranges of pressures and dilutions (Strehlow and Engel 1969). Their data shows that in an $85 \%$ argon- $15 \%$ stoichiometric oxygen/hydrogen mixture at 1 atmosphere pressure, a cell with characteristic $\lambda$ of $0.8 \mathrm{~cm}$ exists. This is the initial gas composition in the shipping, staging, and storage configuration producing a 10 atmosphere detonation wave. Their data also indicates an ambient pressure scaling with $\mathrm{P}$. This small cell size indicates susceptibility to DDT comparable to that of stoichiometric hydrogen-air mixtures. There are no confirming measurements of DDT in these systems at pressures above atmospheric (Ciccarelli 1996). 
Factors favoring initiation are: the initiating cell dimensions are small, all MCOs contain reactive uranium hydride, and mechanical or electrically induced sparks are likely. An initiating event is therefore assumed, and the remaining emphasis is placed upon evaluating detonation wave pressures in the MCOs.

\subsection{FULLY FLOODED CONFIGURATION}

During the fully flooded condition, reactive gas production rates from radiolysis and/or chemical reactions are or can be maximized, and void spaces within the MCO may accumulate hydrogen and oxygen. This flooded configuration must therefore be analyzed for its detonation potential. For this condition, the following parameters are assumed:

- an air gap exists within the MCO head space,

- the initial pressure is one atmosphere,

2 the hydrogen/oxygen ratio is stoichiometric,

- the hydrogen concentration ranges from 0 to $90 \%$ by volume, and

- the temperature range is from 25 to $100{ }^{\circ} \mathrm{C}$.

Under these conditions, the pressure increases shown in Table 1 are calculated. The detonation pressure ratios from Table 1 are presented graphically in Figure 1.

Figure 1 shows that detonation pressures are highest in all cases at 30\% hydrogen by volume, that the pressures decrease with increasing initial temperature, and that several detonation pressures are higher than the nominal 10 atmosphere pressure limit for the MCO. The maximum detonation pressure in the fully flooded configuration is 13 atmospheres produced by a stoichiometric mixture at $0{ }^{\circ} \mathrm{C}$. Pressures in excess of 10 atmospheres are possible for mixtures from 17 to 57 volume percent $\mathrm{H}_{2}$. At higher initial pressures, the mixture range capable of creating a detonation pressure higher than 10 atmospheres, widens beyond 17 to $57 \% \mathrm{H}_{2}$.

The probability of DDT occurring is related to the hydrogen concentration. Although predicting DDT is not an exact science, it is recognized that DDT is most likely to occur within the 17 to 57 volume percent hydrogen range. 
Table 1. Detonation Pressure ratios $\left(\mathrm{P} / \mathrm{P}_{\mathrm{o}}\right)$ for the Flooded MCO.

\begin{tabular}{|c|c|c|c|c|c||}
\hline \multirow{2}{*}{$\begin{array}{c}\text { Volume } \\
\text { Percent } \\
\text { Hydrogen }\end{array}$} & \multicolumn{5}{|c|}{ Temperature $\mathbf{~}^{\circ} \mathbf{C}$ ) } \\
\cline { 2 - 7 } & $\mathbf{2}^{\circ}$ & $\mathbf{2 5}^{\circ}$ & $\mathbf{5 0}^{\circ}$ & $\mathbf{7 5}^{\circ}$ & $\mathbf{1 0 0}^{\circ}$ \\
\hline 0 & - & - & - & - & - \\
\hline 10 & 6.718 & 6.154 & 5.678 & 5.270 & 4.917 \\
\hline 20 & 10.93 & 10.01 & 9.236 & 8.572 & 7.998 \\
\hline 30 & 13.14 & 12.04 & 11.11 & 10.31 & 9.617 \\
\hline 40 & 12.21 & 11.19 & 10.32 & 9.582 & 8.940 \\
\hline 50 & 11.11 & 10.19 & 9.398 & 8.723 & 8.138 \\
\hline 60 & 9.793 & 8.972 & 8.277 & 7.683 & 7.168 \\
\hline 70 & 8.145 & 7.462 & 6.884 & 6.390 & 5.961 \\
\hline 80 & 6.034 & 5.528 & 5.100 & 4.734 & 4.417 \\
\hline 90 & 3.294 & 3.018 & 2.784 & 2.584 & 2.411 \\
\hline
\end{tabular}


Figure 1. Detonation Pressures in Fully Flooded Configurations.

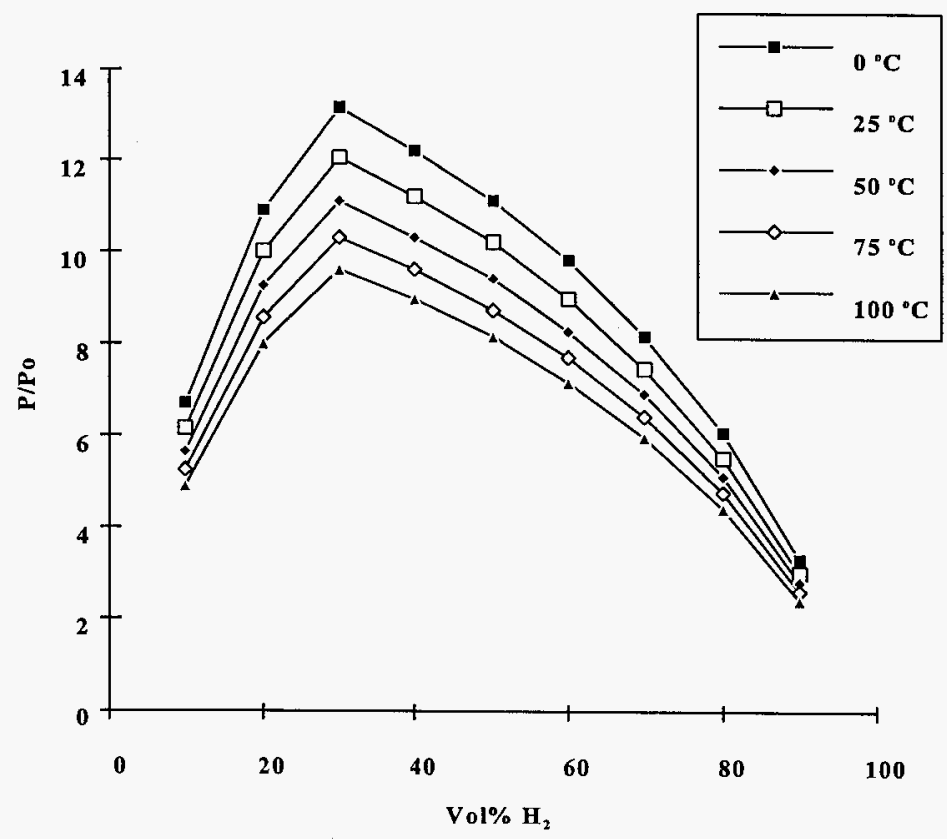


WHC-SD-SNF-TI-021

Revision 0

\subsection{COLD VACUUM DRYING}

The next process condition analyzed was the detonation pressure on the low pressure side of the vacuum pump. The following parameters were assumed for this case:

- Water vapor partial pressure is 15 torr,

- Oxygen partial pressure is 1 torr,

- Nitrogen partial pressure is 4 torr, and

- Hydrogen partial pressure is $1-100$ torr.

Table 2 presents the pressure ratios calculated from equation (7). The Table 2 detonation pressure ratio data are presented graphically in Figure 2.

Table 2. Detonation Pressure Ratio for Vacuum Side of Pump.

\begin{tabular}{|c|c|c|c|}
\hline \multirow{2}{*}{$\mathbf{H}_{2}$ (torr) } & \multicolumn{3}{|c|}{ Temperature $^{\circ} \mathbf{C}$ ) } \\
\cline { 2 - 4 } & $\mathbf{5 0}^{\circ}$ & $\mathbf{7 5 ^ { \circ }}$ & $\mathbf{1 0 0 ^ { \circ }}$ \\
\hline 1 & 2.7001 & 2.5061 & 2.3381 \\
\hline 10 & 3.7483 & 3.4791 & 3.2459 \\
\hline 20 & 3.0582 & 2.8385 & 2.6482 \\
\hline 30 & 2.5654 & 2.3811 & 2.2215 \\
\hline 40 & 2.2006 & 2.0425 & 1.9056 \\
\hline 50 & 1.9220 & 1.7839 & 1.6643 \\
\hline 60 & 1.7034 & 1.5810 & 1.4750 \\
\hline 70 & 1.5279 & 1.4181 & 1.3231 \\
\hline 80 & 1.3842 & 1.2847 & 1.1986 \\
\hline 90 & 1.2646 & 1.1738 & 1.0951 \\
\hline 100 & 1.1636 & 1.0800 & 1.0077 \\
\hline \hline
\end{tabular}


WHC-SD-SNF-TI-021

Revision 0

Figure 2. Detonation Pressures on the Vacuum Side of the Pump.

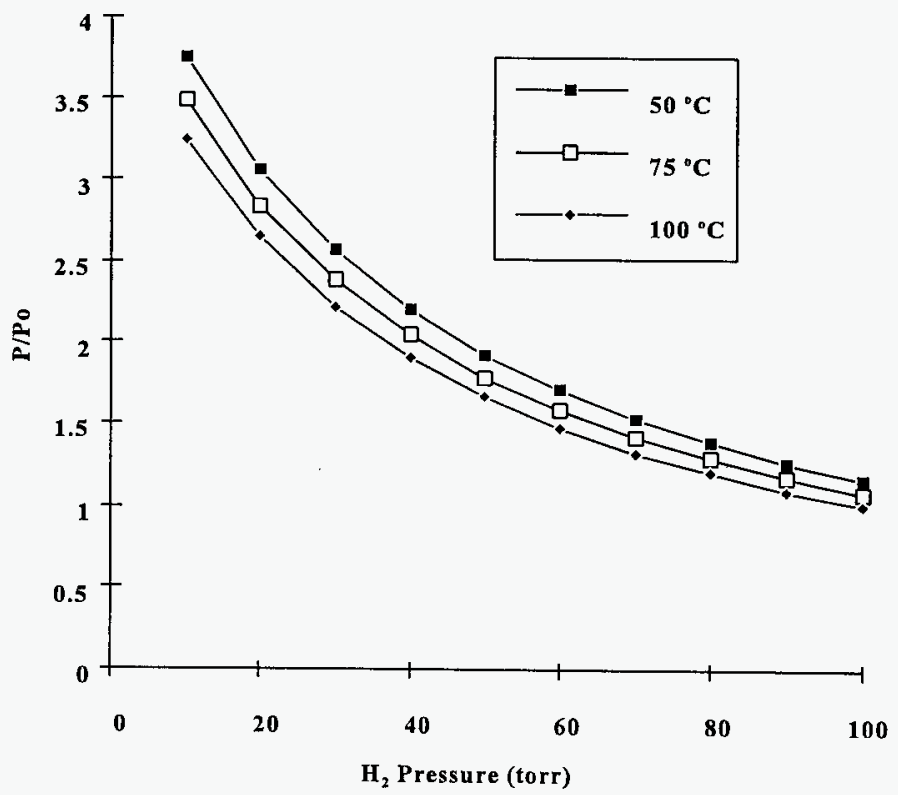


Figure 2 shows that the detonation pressures are quite low on the vacuum side of the pump, and never exceed 0.2 atmosphere. There is therefore no danger of a serious overpressurization of the MCO while under vacuum.

On the pressure side of the pump, the initial parameters are as follows:

- Oxygen partial pressure is $20 \mathrm{kPa}$,

- Nitrogen partial pressure is $80 \mathrm{kPa}$, and

- Hydrogen partial pressure is kept between $0-4 \%$ by dilution.

Under these conditions, the hydrogen detonation pressures are calculated and presented in Table 3. These results are presented graphically in Figure 3.

Table 3. Detonation Pressure Ratios for the Pressure Side of the Pump.

\begin{tabular}{||c|c|c|c||}
\hline \multirow{2}{*}{$\begin{array}{c}\text { Volume Percent } \\
\text { Hydrogen }\end{array}$} & \multicolumn{4}{|c||}{ Temperature $^{\circ} \mathbf{C}$} \\
\hline 0.000 & $\mathbf{5 0}^{\circ}$ & $\mathbf{7 5}^{\circ}$ & $\mathbf{1 0 0}^{\circ}$ \\
\hline 0.005 & - & - & - \\
\hline 0.010 & - & - & - \\
\hline 0.015 & 1.086 & 1.008 & - \\
\hline 0.020 & 1.412 & 1.310 & 1.222 \\
\hline 0.025 & 1.722 & 1.599 & 1.492 \\
\hline 0.030 & 2.020 & 1.875 & 1.749 \\
\hline 0.035 & 2.306 & 2.141 & 1.997 \\
\hline 0.040 & 2.582 & 2.396 & 2.236 \\
\hline
\end{tabular}


Figure 3. Detonation Pressures on the Pressure Side of the Pump.

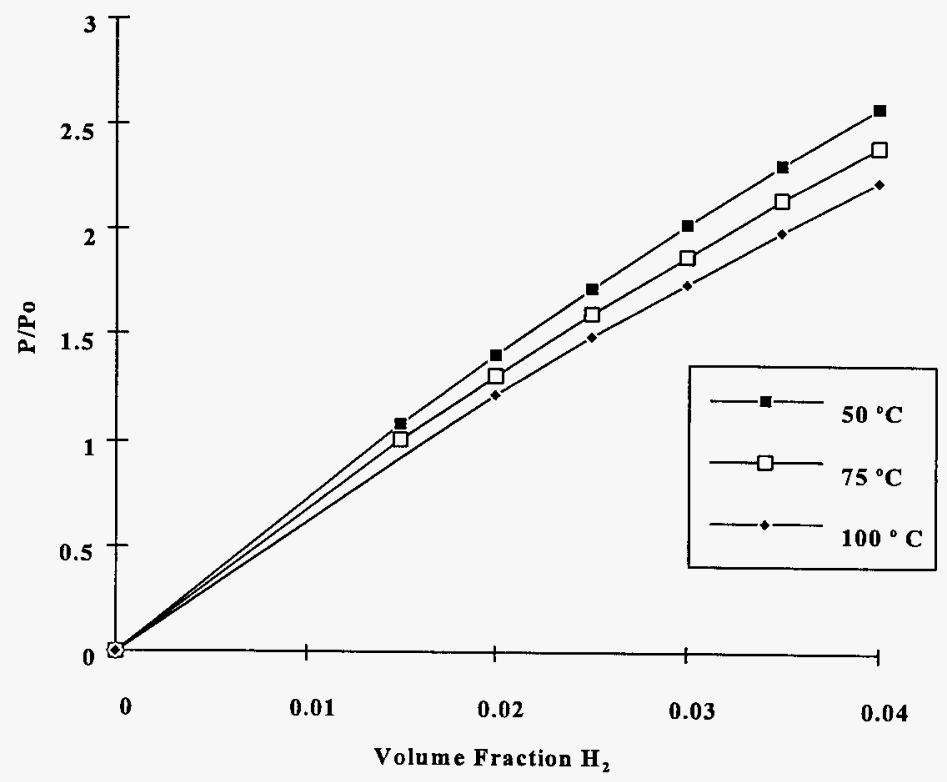


Figure 3 shows that detonation pressures never exceed 3 atmospheres on the pressure side of the pump while the hydrogen volume fraction is maintained less than $4 \%$ by dilution. The exhaust gas plenum must be designed to survive pressure waves of this magnitude.

\subsection{SHIPPING, STAGING, AND STORAGE}

During shipping, staging, and storage the following parameters are assumed:

- The atmosphere is to be inert gas such as argon,

- Initial pressure ranges from 1 to 10 atmospheres,

- Temperature range $=50-150^{\circ} \mathrm{C}$,

- Hydrogen to argon ratio range $=5$, and

- Hydrogen to oxygen ratio equals 1 .

Using these parameters, the detonation pressure ratio was calculated and is presented in Table 4. Table 4 detonation pressure ratios are presented graphically in Figure 4.

Table 4. Detonation Pressure Ratios During Shipping, Staging, \& Storage.

\begin{tabular}{|c|c|c|c|c|c|}
\hline \multirow{2}{*}{$\begin{array}{l}\text { Hydrogen to } \\
\text { Argon Ratio }\end{array}$} & \multicolumn{5}{|c|}{ Temperature ${ }^{\circ} \mathrm{C}$} \\
\hline & $50^{\circ}$ & $75^{\circ}$ & $100^{\circ}$ & $125^{\circ}$ & $150^{\circ}$ \\
\hline 0.01953 & 2.164 & 2.008 & 1.874 & 1.756 & 1.652 \\
\hline 0.0391 & 3.999 & 3.712 & 3.463 & 3.246 & 3.054 \\
\hline 0.0781 & 6.759 & 6.273 & 5.853 & 5.485 & 5.161 \\
\hline 0.1563 & 9.914 & 9.202 & 8.585 & 8.046 & 7.570 \\
\hline 0.3125 & 12.46 & 11.57 & 10.79 & 10.11 & 9.517 \\
\hline 0.6250 & 13.90 & 12.91 & 12.04 & 11.28 & 10.62 \\
\hline 1.25 & 14.47 & 13.43 & 12.53 & 11.74 & 11.05 \\
\hline 5.0 & 14.58 & 13.53 & 12.63 & 11.84 & 11.14 \\
\hline
\end{tabular}


Figure 4. Ratio of Detonation Pressures to Ambient Pressures for Shipping, Staging, and Storage.

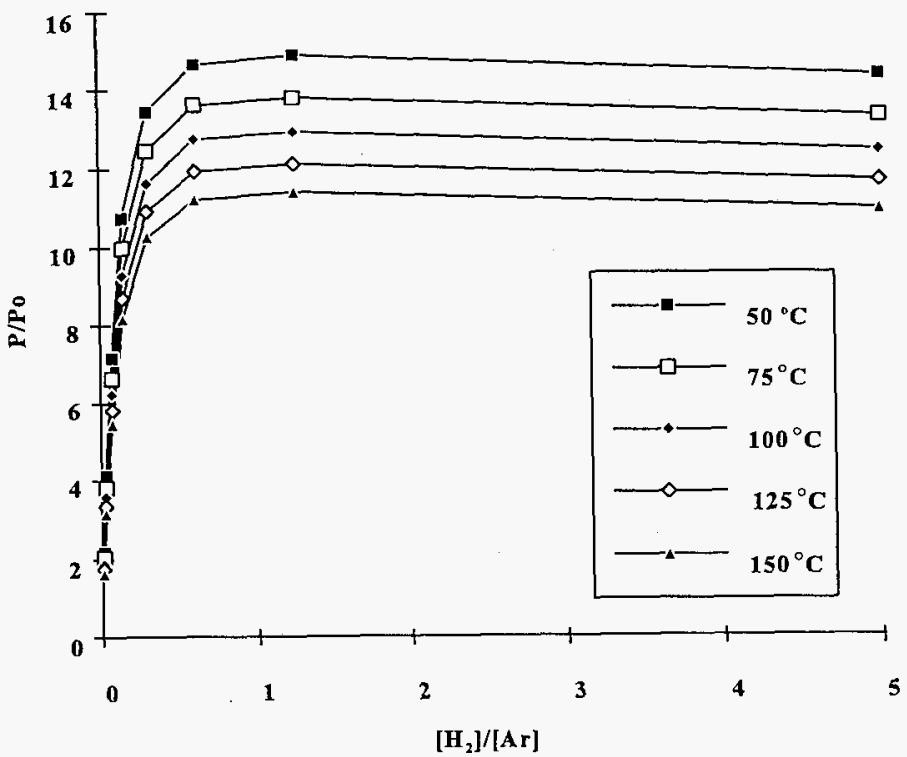

Figure 4 demonstrates that almost all of the pressure ratios are above 10 and are relatively invariant for hydrogen to argon ratios above 0.5 .

Figure 5 shows an interesting correlation between detonation pressure and the amount of water radiolyzed in the MCO. 
WHC-SD-SNF-TI-021

Revision 0

Figure 5. Detonation Pressures with Varying Amounts of Water.

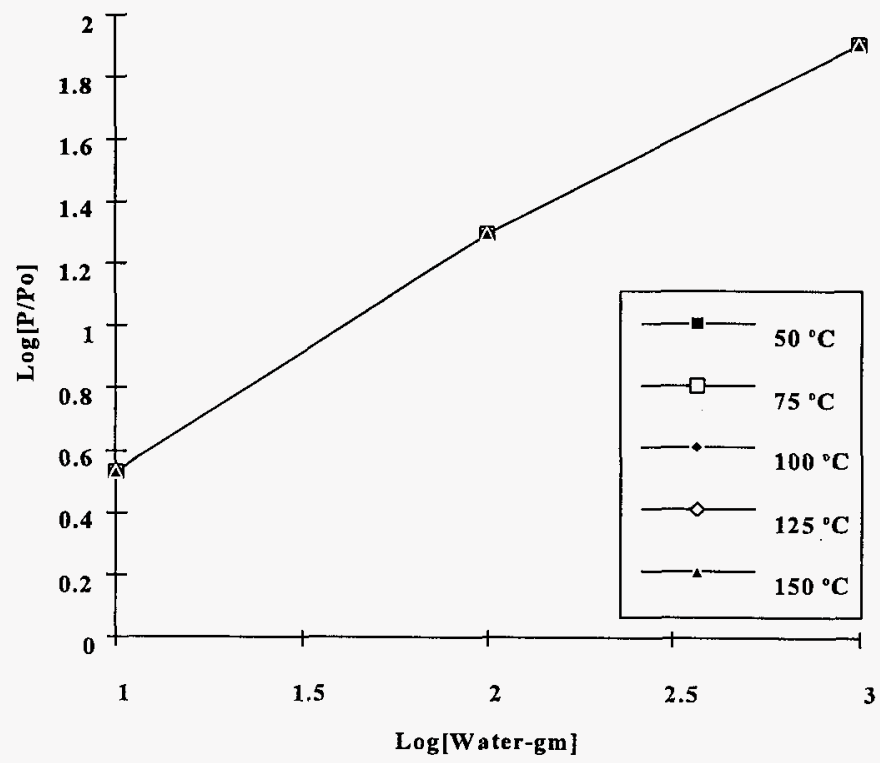

According to Figure 5, only 42 grams of water radiolyzed in the $\mathrm{MCO}$, are required to potentially produce a 10 atmosphere detonation wave. Since the $M C O$ will contain over 6 tons of fuel, verifying that the MCO contains less than 42 grams of water seems a daunting challenge. 


\subsection{SUMMARY}

Ignition and subsequent detonation of hydrogen/oxygen mixtures in the MCOs is presented as a distinct possibility. Two items of value may be gleaned from this discussion, the first is the relative probability of either deflagration or detonation, and the second is the maximum pressures achieved in a detonation.

Although this report has not discussed the first item in detail (the probability of deflagration or DDT), it should be recognized that such deflagration or DDT is relatively more probable in the upper half of the area below each of the pressure ratio curves in Figure 1. The probability also increases for hydrogen/oxygen mixtures, as the hydrogen to argon molar ratio increases toward 1, as shown in Figure 4.

Given the possibility of an ignition leading to detonation, the main focus of this paper has been on the thermodynamic energy potential of the system and the detonation pressures that would be achieved. It has been shown that many of these system configurations can achieve 10 atmospheres or more in the detonation wave. It has also been shown that during long-term storage, the radiolysis of only 42 grams of water is required to produce a hydrogen/oxygen mixture that yields a 10 atmosphere detonation wave. It will be a daunting challenge to prove that the system does not contain 42 or more grams of water when placed in long-term storage. 


\subsection{REFERENCES}

Chase, M.W., et. al., 1986, JANAF Thermochemical Tables, Third Edition, American Institute of Physics, New York, New York.

Ciccarelli, G. et. al., 1984, High Temperature Hydrogen-Air-Steam Detonation Experiments in the BNL Small Scale Development Apparatus, NUREG/CR-6213, BNL-NUREG-52414.

Fickett, W. and Davis, W.C., 1979, Detonation, University of California Press, Berkeley, California.

Landau, L.D. and Lifshitz E.M., 1993, Fluid Mechanics, Pergamon Press.

Lee, J.H.S., 1984, Dynamic Properties of Gaseous Detonations, Fluid Mechanics, 311.

Sokalek, A.S., 1960, Self-Ignition Flame and Detonation in Gases. Translated by the Israel Program for Scientific Translations, Jerusalem, Israel, 1963. Published for the U.S. National Aeronautics and Space Administration and the National Science Foundation, Washington D.C.

Spencer, H.M., 1945, JACS 67, 1858.

Strehlow, R.A. and Engel, C.D., 1969, Transverse Waves in Detonation II. Structure and Spacing in H2-O2 Systems, AIAA 7492.

Wilson, W., 1996, Private Communication, Science Applications International Corporation, San Diego, California. 
WHC-SD-SNF-TI-021

Revision 0

\section{APPENDIX}

\section{DETONATION WAVE THEORY}

Equation (7) in the main text was presented and used to generate the detonation pressure ratios without a derivation or other proof of validity. Its derivation cannot be given in this appendix, since we do not have ready access to the source material. As a secondary position, the following derivation of equations yielding detonation pressure ratios are presented from SelfIgnition Flame and Detonation of Gases (Sokalek 1960). Sokalek's treatment does not yield equation (7) in directly recognizable form; however, it is shown that it is numerically equivalent.

\section{Simple Shock Wave}

A shock wave may be represented as the result of the very rapid compression of gas enclosed in an infinitely long tube, by a piston moving at a constant velocity u. During the course of one second in which the piston has moved a distance of $u$, the disturbance caused by the compression travels a distance $\mathrm{C}$ at the high, but finite velocity $\mathrm{C}$. In such a case, the undisturbed gas is separated from the compressed gas by a boundary across which there exists an abrupt discontinuous change in all of the parameters characterizing the state of the gas: the pressure, density, specific volume, temperature and velocity. This boundary represents the shock wave front. $\mathrm{C}$ then, is the propagation velocity of the shock wave with respect to the undisturbed gas; $\mathrm{u}$ is the velocity of the piston and of the gas flow behind the shock front; and c-u is the propagation velocity of the shock wave with respect to the compressed gas.

The application of the conservation laws to the states of the undisturbed and the compressed gas (denoted by the subscripts of 0 and 1) leads to three equations: The mass conservation equation:

$$
\text { or } \begin{aligned}
\mathrm{Cp}_{\mathrm{o}} & =(\mathrm{C}-\mathrm{U}) * \mathrm{P}_{1}=\mathrm{M} \\
\mathrm{C} / \mathrm{V}_{\mathrm{o}} & =(\mathrm{C}-\mathrm{U}) / \mathrm{V}_{1}=\mathrm{M}
\end{aligned}
$$

The momentum conservation equation

or

$$
\mathrm{Cp}_{\mathrm{o}}^{*} \mathrm{u}=\rho_{1}-\rho_{\mathrm{o}}
$$

$$
C^{*} U / V_{0}=\rho_{1}-\rho_{0}
$$

and the energy conservation equation:

$$
\text { or } \begin{aligned}
\mathrm{P}_{1} * \mathrm{u} & =\mathrm{P}_{\mathrm{o}}{ }^{*} \mathrm{C}^{*}\left(\mathrm{E}_{1}-\mathrm{E}_{\mathrm{o}}+\mathrm{u}^{\wedge} 2 / 2\right) \\
\mathrm{P}_{1} * \mathrm{u} & =\mathrm{C} / \mathrm{V}_{\mathrm{o}} *\left(\mathrm{E}_{1}-\mathrm{E}_{\mathrm{o}}+\mathrm{u}^{2} / 2\right)
\end{aligned}
$$


The quantity $\mathrm{M}$, in equation (A1), is the mass of gas passing through $1 \mathrm{~cm}^{2}$ of the shock wave surface during one second and is usually known as the mass gas velocity (mass-flow rate).

Equation (A3) states that the work done on the gas equals the increment in its internal and kinetic energies. Here $\rho$ is the density, $V$ is the specific volume, and $E$ is the internal energy per unit mass of gas. Equations (A1) and (A2) show the ratio between $u$ and $C$, and also give these quantities as functions of $\mathrm{P}$ and $\mathrm{V}$ :

$$
\mathrm{u}=\mathrm{C}\left(\mathrm{V}_{1} \cdot \mathrm{V}_{0}\right) / \mathrm{V}_{1}=\mathrm{C}\left(\mathrm{P}_{1}-\mathrm{P}_{0}\right) / \mathrm{P}_{1}=\left(\mathrm{V}_{0}-\mathrm{V}_{1}\right)^{*} \sqrt{P_{1}-P_{0} / V_{0}-V_{I}}
$$

and

$$
\mathrm{C}=\sqrt{\left(P_{I}^{-} P_{0}\right)\left(1 / V_{0}^{-} I / V_{1}\right)}=V_{0} \sqrt{\left(P_{I}^{-} P_{0}\right) /\left(V_{0}^{-} V_{1}\right)}
$$

If $\mathrm{C}$ and $\mathrm{u}$ from equations (A4) and (A5) are substituted into equation (A3), the energy conservation equation becomes:

$$
E_{1}-E_{0}=\left(V_{0}-V_{3}\right) *\left(P_{1}+P_{0} / 2\right)
$$

For an ideal gas, the internal energy is:

$$
E=P * V / k-1
$$

So,

$$
\left.\left(\mathrm{P}_{1} * \mathrm{~V}_{1} /(\mathrm{k}-1)\right)-\left(\mathrm{P}_{0} * \mathrm{~V}_{0} /(\mathrm{k}-1)\right)=\left(\mathrm{P}_{1}+\mathrm{P}_{0}\right) / 2\right)^{*}\left(\mathrm{~V}_{0}-\mathrm{V}_{1}\right)
$$

which may be transformed into:

$$
\frac{V_{0}}{V_{I}}=\frac{(k+1) P_{I} / P_{0}+(k-1)}{(k-1) P_{1} / P_{0}+(k+1)}
$$

giving the relation between the degree of compression ratio, $\varepsilon=V_{0} / V_{1}=\rho_{1} / \rho_{0}$ and the pressure rise $\pi=P_{1} / P_{0}$ in the shock wave. Equations (A6) and (A9) are the equations for the dynamic compression in a shock wave and are known as the Hugoniot adiabatic $\left(\mathrm{H}_{\mathrm{sh}}\right)$. Equation (A6) leads to some expressions that are useful for determining the relative pressure rise $\pi$ and temperature rise $\mathbf{v}$ as functions of the compression ratio $\varepsilon$.

$$
\pi=\frac{\epsilon(k+1)-(k-1)}{(k+1)-\epsilon(k-1)}
$$


now since:

$$
\begin{aligned}
& \mathrm{T}_{1} / \mathrm{T}_{0}=\mathrm{P}_{1} \mathrm{~V}_{1} / \mathrm{P}_{0} \mathrm{~V}_{0} \\
& 0=\pi / \varepsilon=(1 / \varepsilon)((\varepsilon(\mathrm{k}+1)-(\mathrm{k}-1)) /((\mathrm{k}+1)-\varepsilon(\mathrm{k}-1))
\end{aligned}
$$

Finally the quantities $\mathrm{C}$ and $\mathrm{u}$ can also be expressed as functions of $\varepsilon$ and $\pi$ :

$$
C^{2}=\left(P_{0} V_{0}\right)(\pi-1) /(1-1 / \varepsilon)
$$

and

$$
\mathrm{U}^{2}=\mathrm{P}_{\mathrm{o}} \mathrm{V}_{\mathrm{o}}(1-1 / \varepsilon)(\pi-1)
$$

for strong shock waves in which $\pi>10$, the terms $(k-1)$ and $(k+1)$ in the numerator and denominator of equation (A9) may be neglected so that:

$$
\varepsilon \approx(\mathrm{k}+1) /(\mathrm{k}-1)
$$

consequently,

$$
\mathrm{C}^{2}=\mathrm{P}_{\mathrm{o}} \mathrm{V}_{\mathrm{o}}((\mathrm{k}+1) / 2)(\pi-1)
$$

or

$$
\left(\mathrm{C} / \mathrm{C}_{\mathrm{o}}\right)^{2}=(\mathrm{k}+1 / 2 \mathrm{k})(\pi-1)
$$

if it is taken into account that:

$$
\mathrm{NRT}_{0}=\mathrm{C}_{\mathrm{o}}{ }^{2} / \mathrm{k} \text { or } \mathrm{k}=\mathrm{C}_{\mathrm{o}}{ }^{2} / \mathrm{P}_{0} \mathrm{~V}_{\mathrm{o}}
$$

where $\mathrm{C}_{0}$ is the velocity of sound in the gas in its initial state.

Let us now consider the main differences between dynamic compression in a shock wave and ordinary adiabatic compression according to the Poisson law:

$$
\left(\mathrm{V}_{\mathrm{o}} / \mathrm{N}_{1}\right)^{\mathrm{k}}=\mathrm{P}_{1} / \mathrm{P}_{0}
$$

These differences exist because the compression in a shock wave occurs with a finite displacement and mass flow rate, while in ordinary compression these quantities are infinitesimal. 
WHC-SD-SNF-TI-021

Revision 0

\section{The Stationary Detonation Wave}

A detonation wave, which is a shock wave accompanied by reaction, is described by the same conservation equations as a simple shock wave. But, it has an additional term, representing the heat of chemical reaction, included in the energy conservation equation:

$$
E_{1}-E_{0}=\left(V_{0}-V_{1}\right)\left(P_{0}+P_{1}\right) / 2+Q
$$

The conservation of momentum in the equation analogous to (A2) and the conservation of energy in equation (A19) refer to the initial and final reaction states (complete liberation of the reaction energy), namely to the fresh gas ahead of the detonation wave front, and to the reaction products behind the front, after thermodynamic equilibrium has been established. If the change in the internal energy is once again written as:

$$
\Delta \mathrm{E}=\Delta(\mathrm{PV}) /(\mathrm{k}-1),
$$

then the pressure as a function of the specific volume during shock compression, with simultaneous energy liberation due to reaction, is given by the equation for the Hugoniot adiabatic describing a combustion wave:

$$
\mathrm{P}_{1} \mathrm{~V}_{1}-\mathrm{P}_{0} \mathrm{~V}_{0} /(\mathrm{k}-1)=\left(\mathrm{V}_{0}-\mathrm{V}_{1}\right)\left(\mathrm{P}_{0}+\mathrm{P}_{1}\right) / 2+\mathrm{Q}
$$

This equation can be rewritten as:

$$
\begin{array}{r}
\pi=(\varepsilon(k+1)-(k-1)) /((k+1)-\varepsilon(k-1))+ \\
2 Q \varepsilon(k-1) /(\operatorname{PoVo}[(k+1)-\varepsilon(k-1)]
\end{array}
$$

and when it is taken into account that the multiplier of $Q$ for $\varepsilon<6$ is greater than 0 , it is evident that $\pi$ for the dynamic compression in a detonation wave is higher than the corresponding $\pi$ in a shock wave without reaction. Figure A-1 contains two Hugoniot adiabatic plots of pressure versus volume for a simple shock wave and for a detonation wave. 
WHC-SD-SNF-TI-021

Revision 0

Figure A-1. Shock Waves: 1. (in the Absence of Reaction) AZ and 2. For a Combustion Wave GFEDB

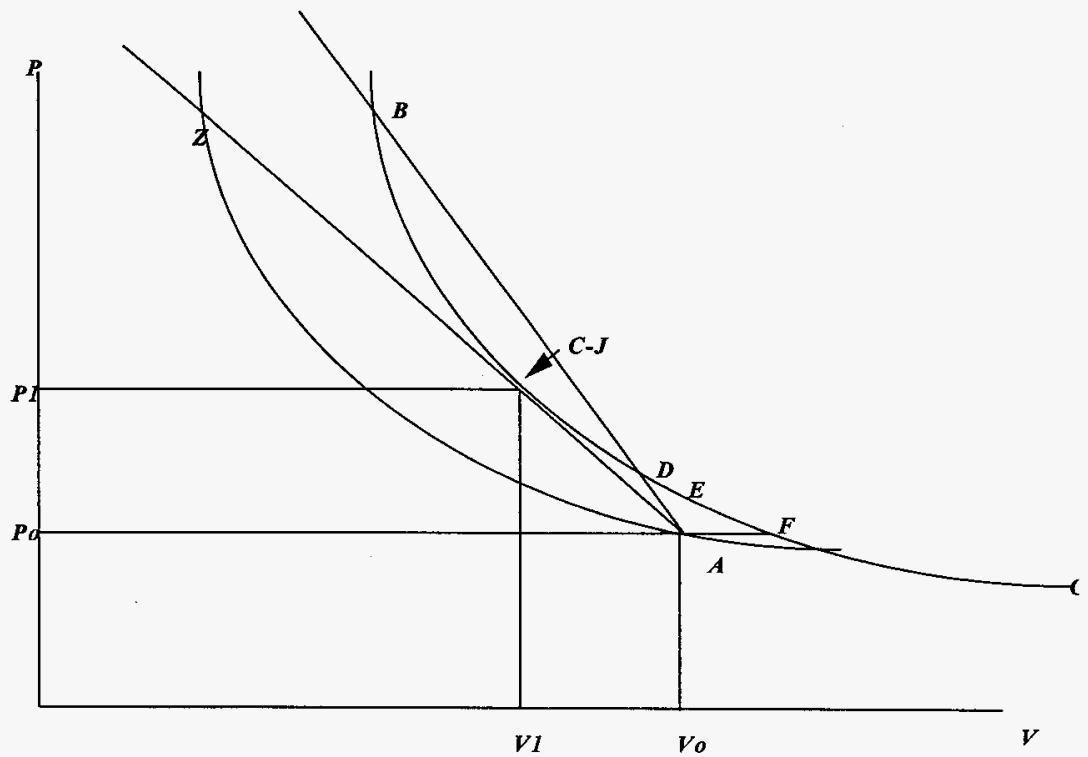

The Hugoniot adiabatic for a combustion wave in which $\varepsilon<6$ lies above the adiabatic of a simple shock wave, which passes through point $\mathrm{A}$ describing the initial state $(\mathrm{Po}, \mathrm{Vo})$, is shown clearly in Figure A-1. The propagation velocity D of the detonation wave and the gas flow velocity $\mathrm{u}$ for the $\mathrm{H}$ adiabatic in the presence of combustion are determined by formulas similar to (A4), (A5), (A12), and (A13) for a simple shock wave, but in which $\mathrm{C}$ is replaced by $\mathrm{D}$, the velocity of a detonation wave.

Each point on the $H$ adiabatic corresponds to specific values of $D$ and $u$. Nevertheless, experiments show that for a given composition and initial state of combustible mixture there is one single, completely determined value of the detonation-wave velocity, which is independent of all other experimental conditions. Consequently, the basic problem of detonation-wave theory has been to find a criterion for selecting the point on the $\mathrm{H}$ curve that indicates the unique value of the velocity of a stationary detonation wave. Following Jouguet, let us now examine three portions of the $\mathrm{H}$ adiabatic for combustion. 
1. The portion below point $\mathrm{F}$ corresponds to combustion accompanied by a lowering of pressure and an increase in specific volume, just as in flame propagation by means of heat conduction and diffusion. The propagation velocity of a combustion wave for any point on the $\mathrm{H}$ adiabatic, just as for the adiabatic of a simple shock wave, may be determined from equation (A4) as the product of the initial specific volume times $\sqrt{\left(p_{1}-p_{0}\right) /\left(v_{0}-v_{1}\right)}$, the square root of the slope of the line connecting the given point on the $\mathrm{H}$ adiabatic with $\mathrm{A}$, the point corresponding to the initial state. The graph indicates that for all points below $F, \sqrt{\left(p_{1}-p_{0}\right) /\left(v_{o}-v_{1}\right)}<(\partial p / \partial v)_{0}$, where $(\partial p / \partial v)_{0}$ is the slope at the point corresponding to the initial state. Consequently,

$<\mathrm{V}_{\mathrm{o}} \sqrt{\left(p_{1}-p_{0}\right) /\left(v_{0}-v_{1}\right)}<\mathrm{V}_{0} \sqrt{-(\partial p / \partial v)_{0}}$

where the right side represents the velocity of sound in the gas head of the combustion wave. Evidently, all of the curve below $\mathrm{F}$ corresponds to flames propagating at subsonic velocities, generally referred to as deflagration.

2. In portion EF. a pressure increase is accompanied by an increase in specific volume. Since for $\left(p_{1}-p_{0}\right)>0$ and $\left(v_{0}-v_{1}\right)<0, \sqrt{\left(p_{1}-p_{0}\right) /\left(v_{0}-v_{1}\right)}$ is imaginary, region EF does not correspond to any real type of flame propagation.

3. The portion above point $\mathrm{E}$ corresponds to combustion accompanied by a pressure rise and a decrease in specific volume, similar to the change in $p$ and $v$ in a shock wave. A comparison between $\tan \alpha$ at point $A$ and the slopes of lines drawn from point $A$ to points on this branch indicates that the wave velocity for the entire EB branch is higher than the velocity of sound. Consequently, only the branch of the $\mathrm{H}$ curve lying above point $\mathrm{E}$ corresponds to a combustion wave with shock-wave properties (dynamic, or shock, compression and a supersonic propagation velocity). Chapman observing that of all the lines drawn from the initial state point $\mathrm{E}$, only one unique point on branch $\mathrm{EBN}$ corresponds to a tangent, formulated a rule defining the parameters of a stationary detonation wave. These parameters are given in terms of coordinates $(\mathrm{p} 1, \mathrm{v} 1)$ as the point at which the Hugoniot adiabatic for a shock wave accompanied by combustion is tangent to a line drawn from the initial-state point.

The point of tangency is called the Chapman-Jouguet (C-J) point, after the founders of the classical theory of the detonation wave. This rule merely is a statement of the experimentally established fact that for a given mixture and given initial conditions, there is a unique value of the detonation-wave velocity, and is essentially an empirical rule. To justify the rule, Jouguet began with the fact that, in spite of all the various possible combustion waves with supersonic propagation velocities corresponding to different points on the considered branch of the $\mathrm{H}$ curve, a detonation wave is distinguished by a stationary nature.

If a detonation wave is to remain stable, the shock wave causing the detonative ignition in successive gas layers must not be weakened by the rarefaction waves formed during the 
WHC-SD-SNF-TI-021

Revision 0

expansion following the completion of combustion behind the detonation wave front. These waves, just as any disturbance, are propagated through the stream behind the detonation wave front at the velocity of sound:

$$
c_{1}=v_{1} \sqrt{-(\partial p / \partial v)_{1}}
$$

corresponding to the state of the burned gas; relative to the fresh gas this propagation takes place at the local velocity of sound $\left(c_{1}+u\right)$. Consequently, a detonation wave will not be affected by rarefaction waves only when:

$$
\mathrm{D}>\mathrm{c}_{1}+\mathrm{u}
$$

Since, as shown directly by equations (A3) and (A4),

$$
\mathrm{D}-\mathrm{U}=\mathrm{v} 1 \quad \sqrt{\left(p_{1}-p_{0}\right) /\left(v_{o}-v_{1}\right)}
$$

is the velocity of the stream of compressed gas particles relative to the detonation-wave front, the condition for stability of the detonation wave, is that the velocity of the stream of compressed gas behind the detonation wave must be not less than the velocity of sound in the given gas, since this is the propagation velocity of rarefaction waves in the gas. This condition for stability of a detonation wave, formulated by Jouguet, provides a partial verification of the Chapman rule. As seen from Figure A- $1, \quad\left(p_{1}-p_{0}\right) /\left(v_{0}-v_{1}\right)$ is the slope of the secants drawn from A, while the quantity, $(\partial p / \partial v)$, in equation (A23), represents the slopes of the tangents to different points on the $\mathrm{H}$ curve.

Above the C-J point, the angles made by the scants are smaller than those made by the tangents, while below the $\mathrm{C}-\mathrm{J}$ point, the reverse is true; thus:

$$
\begin{aligned}
& \text { above the C-J point (CJ-B branch), } D<c_{1}+u \\
& \text { below the C-J point }\left(C j-E \text { branch), } D>c_{1}+u\right. \\
& \text { at the C-J point, } D=c_{1}+u
\end{aligned}
$$

The stability condition (A24) is not fulfilled on the branch of the $\mathrm{H}$ adiabatic above the C-J point; it is fulfilled only at the C-J point and below it (on branch E-CJ). It follows from (A25) that the $\mathrm{C}$-J point corresponds to the minimum of all the possible wave velocities along this branch, whereas the minimum shock-wave velocity corresponds to the minimum amount of kinetic-energy dissipation due to viscosity forces (that is, the minimum entropy increase in the transition from the initial state). The choice of a point on the $\mathrm{H}$ adiabatic determining the state of the gas in the detonation wave, just as in the classical theory of detonation waves in general, was 
made without any considerations associated with the chemical reaction rate in the detonation wave. It may be assumed, although this was not formulated explicitly, that the classical theory presupposes an essentially instantaneous chemical transformation after adiabatic compression of the mixture in the shock wave.

Jost observed that, for a finite reaction-zone width, compression waves of finite amplitude (that is, corresponding to a finite increment in mass flow velocity) were generated in the combustion zone at a certain distance from the shock-wave front (Sokalek 1960), their velocity is only slightly greater than the local velocity of sound, these waves cannot reach the shock-wave front, as long as its velocity is appreciably greater than the local velocity of sound (that is, below the C-J point); the compression waves continuously overtake the shock-wave front only at the C-J point. As a result, the choice of the point of tangency (C-J) between the $\mathrm{H}$ adiabatic and the line drawn from the initial-state point is justified by the fact that only at this point are the conditions completely fulfilled for stability of propagation of a detonation wave.

This is true for the following reasons: 1 ) above the C-J point, the shock wave is continuously attenuated by the action of the rarefaction waves formed after combustion; 2) below the $\mathrm{C}-\mathrm{J}$ point, the finite-amplitude compression waves formed during combustion cannot reach the shock-wave and compensate the losses in kinetic energy due to dissipation; 3) only at the C-J point is it impossible for the shock-wave to become attenuated, and only here are the losses in the wave definitely compensated.

The Chapman-Jouguet rule leads directly to a method for calculating the velocity and other parameters of a detonation wave.

At the C-J point, the wave velocity (D-u) with respect to the compressed gas is equal to the velocity of sound $\left(c_{1}\right)$ in this gas, that is, the dynamic adiabatic is tangent to the Poisson adiabatic for the given initial state $\left(\mathrm{p}_{1}, \mathrm{v}_{1}\right)$ :

$$
\left(p_{1}-p_{0}\right) /\left(v_{0}-v_{1}\right)=-(\partial p / \partial v)_{1} \quad=\mathrm{k}_{1} \mathrm{p}_{1} / \mathrm{vl}
$$

from which,

$$
\mathrm{D}=v_{o} \sqrt{\left(p \rho_{0}\right) /\left(v_{o}-v_{1}\right)}=v_{o} \sqrt{k_{1} p_{1} / v_{1}}=\varepsilon \sqrt{k_{1} n_{1} R T_{1}}
$$

When condition (A26) is combined with the equation for the $\mathrm{H}$ adiabatic for combustion, it is possible to evaluate $\varepsilon$ and $n_{1} T_{1}$ in equation (A27).

If equation (A26) is written as:

$$
\left(p_{1}-p_{0}\right) / p_{1}=k_{1}\left(v_{0}-v_{1}\right) / v_{1}
$$


or

$$
1-\mathrm{p}_{o} / \mathrm{p}_{1}=1-\mathrm{n}_{0} \mathrm{R}_{0} \mathrm{~T}_{0} / \mathrm{n}_{1} \mathrm{R}_{1} \mathrm{~T}_{1} \varepsilon=\mathrm{k}_{1}(\varepsilon-1)
$$

then we obtain:

$$
K_{1} e^{2}-\varepsilon\left(K_{1}+1\right)+n_{0} R_{0} T_{0} / n_{1} R_{1} T_{1}=0
$$

where $\mathrm{n}_{0}$ and $\mathrm{n}_{1}$ are the number of moles in a gram of mixture before and after combustion, and $k_{1}=C_{p} / C_{v}$ for the state of the gas at the C-J point. The previous equation, together with the equation for the $\mathrm{H}$ adiabatic:

$$
\begin{aligned}
& C_{v 1}\left(T_{1}-T_{0}\right)=Q+1 / 2\left(P_{1}+P_{0}\right)\left(v_{0}-v_{1}\right)= \\
& =Q+1 / 2\left(n_{0} R_{0} T_{0} / n_{1} R_{1} T_{1}-1\right)\left(n_{1} R_{1} T_{1}+n_{0} R_{0} T_{0} / \varepsilon\right)
\end{aligned}
$$

represent a system of two equations that makes it possible to calculate $k_{1}, n_{1}, T_{1}$, and $\varepsilon$ and thus, to define the velocity and other parameters of the detonation wave. Equation (A26) can be rearranged to obtain:

$$
\pi=\mathrm{p}_{\mathfrak{l}} / \mathrm{p}_{0}=1 /\left(1-\mathrm{k}_{\mathrm{l}}(\varepsilon-1)\right)
$$

\begin{tabular}{|c|c|c|c|}
\hline \multicolumn{2}{|c|}{$\begin{array}{l}\text { Initial Gas } \\
\text { Composition }\end{array}$} & \multicolumn{2}{|c|}{$\begin{array}{l}\text { Final Gas } \\
\text { Composition }\end{array}$} \\
\hline \multicolumn{2}{|c|}{ Temp. $300^{\circ} \mathrm{C}$} & & \\
\hline $\mathbf{H}_{2}$ & $=2$ moles & $\mathrm{H}_{2}$ & $=0$ moles \\
\hline $\mathrm{O}_{2}$ & $=1 \mathrm{~mole}$ & $\mathrm{O}_{2}$ & $=0 \mathrm{~mole}$ \\
\hline $\mathbf{N}_{2}$ & $=4$ moles & $\mathrm{N}_{2}$ & $=4$ moles \\
\hline $\mathbf{A}$ & $=0$ moles & $\mathbf{A}$ & $=0$ moles \\
\hline $\mathrm{H}_{2} \mathrm{O}$ & $=0$ moles & $\mathrm{H}_{2} \mathrm{O}$ & $=2$ moles \\
\hline
\end{tabular}

Since the derivations of equation (7) in the main text and (A31) have taken different paths, their equivalency is not obvious and will be tested by calculating the detonation pressure ratio $\pi$ for a single case and comparing the results.

Let us consider the following case: 
Now to solve this problem for the detonation pressure ratio via equation (7) from the main text:

$$
\pi=2 *\left(\gamma_{2}-1 / \gamma_{1}-1\right)^{*}\left(Q / C_{v 1} * T_{1}\right)
$$

we must find suitable expressions for each variable:

$$
\gamma_{2}=\mathrm{K}_{1}=\mathrm{C}_{\mathrm{p}} / \mathrm{Cvl}
$$

where $\mathrm{C}_{\mathrm{p} 1}$ is the system molar heat capacity at constant pressure and $\mathrm{C}_{\mathrm{v} 1}$ is the system molar heat capacity at constant volume, with both terms evaluated at equilibrium:

$$
\gamma_{1}=\mathrm{C}_{\mathrm{po}} / \mathrm{C}_{\mathrm{vo}}
$$

Similarly, these terms are as defined above except that they are evaluated in the initial condition.

$$
\begin{aligned}
& Q=\text { System enthalpy } \\
& T_{1}=\text { equilibrium gas temperature }
\end{aligned}
$$

Now the individual molar heat capacities at constant pressure are calculated using the following formulas:

$$
\mathrm{C}_{\mathrm{p}}=\mathrm{A}+\mathrm{BT}=\mathrm{CT} 2
$$

where the coefficients A, B, and C for each gas are given by H. Spencer (Spencer 1945).

The heat capacity for each gas is calculated by multiplying the molar heat capacity by the number of moles of each gas. Finally, the system heat capacity at constant pressure is determined by adding the heat capacity of each gas. In this manner:

$$
\mathrm{C}_{p o} \text { is calculated to be } 48.45095
$$

since

$$
\begin{aligned}
& C_{v o}=C_{p o}-n * R \\
& C_{v 0}=48.45095-7 * 1.987 \\
& =34.54076
\end{aligned}
$$

and 


$$
\gamma_{1}=C_{p o} / C_{v o}=1.402718
$$

Now $T_{1}$ is the equilibrium gas temperature and is given by:

$$
\mathrm{T}_{\mathrm{t}}=2 * \mathrm{Q}^{*} \gamma_{2} / \mathrm{C}_{\mathrm{v} 1} *\left(\gamma_{2}+1\right)
$$

This equation cannot be solved straightforwardly since the heat capacities are also functions of $\mathrm{T}_{1}$; therefore an iterative solution is determined that gives:

$$
\begin{aligned}
& \mathrm{T}_{1}=2321.5^{\circ} \mathrm{K} \\
& \mathrm{C}_{\mathrm{pl}}=65.92372 \\
& \mathrm{C}_{\mathrm{v}}=54.00070 \\
& \gamma_{2}=1.22079
\end{aligned}
$$

so finally from equation (7) in the main text:

$$
\begin{aligned}
& \pi=2 *\left(\left(\gamma_{2}-1\right) /\left(\gamma_{1}-1\right)\right)^{*}\left(\mathrm{Q} / \mathrm{C}_{\mathrm{v} 1} * \mathrm{~T}_{1}\right) \\
& =12.0663
\end{aligned}
$$

Now this solution will be compared with the value determined from Sokalek's derivation. From Sokalek, we have equations (A29) and (A30):

$$
\begin{aligned}
& \mathrm{K}_{1} \varepsilon^{2}-\varepsilon\left(\mathrm{K}_{1}+1\right)+\mathrm{n}_{0} \mathrm{R}_{0} \mathrm{~T}_{0} / \mathrm{n}_{1} \mathrm{R}_{1} \mathrm{~T}_{1}=0 \\
& \mathrm{C}_{\mathrm{v} 1}\left(\mathrm{~T}_{1}-\mathrm{T}_{0}\right)=\mathrm{Q}+1 / 2\left(\mathrm{n}_{0} \mathrm{R}_{0} \mathrm{~T}_{0} / \mathrm{n}_{1} \mathrm{R}_{1} \mathrm{~T}_{1}-1\right)\left(\mathrm{n}_{1} \mathrm{R}_{1} \mathrm{~T}_{1}+\mathrm{n}_{0} \mathrm{R}_{0} \mathrm{~T}_{0} / \varepsilon\right)
\end{aligned}
$$

Since we already have solved for $K_{1}$ which is also $\gamma_{2}$, and $C_{v 1}$, we can substitute these into equations (A28) and (A29). This leaves 2 equations with 2 unknowns, $\varepsilon$ and $T_{1}$, and simultaneous solutions can be obtained.

thus Sokalek's $\mathrm{T}_{1}$ is $2412.5^{\circ} \mathrm{K}$ and $\varepsilon$ is 1.75128

From Sokalek's equation (A30)

$$
\begin{aligned}
& \pi=p_{1} / p_{0}=1 /\left(1-k_{1}(\varepsilon-1)\right) \\
& =1 /\left(1+k_{1}-k_{1}{ }^{*} \varepsilon\right) \\
& =12.071
\end{aligned}
$$


WHC-SD-SNF-TI-021

Revision 0

This value for $\pi$ can be compared to the value, 12.066 calculated above from equation (7) and establishes the numerical equivalency of the two methods for calculating detonation pressure ratios. 


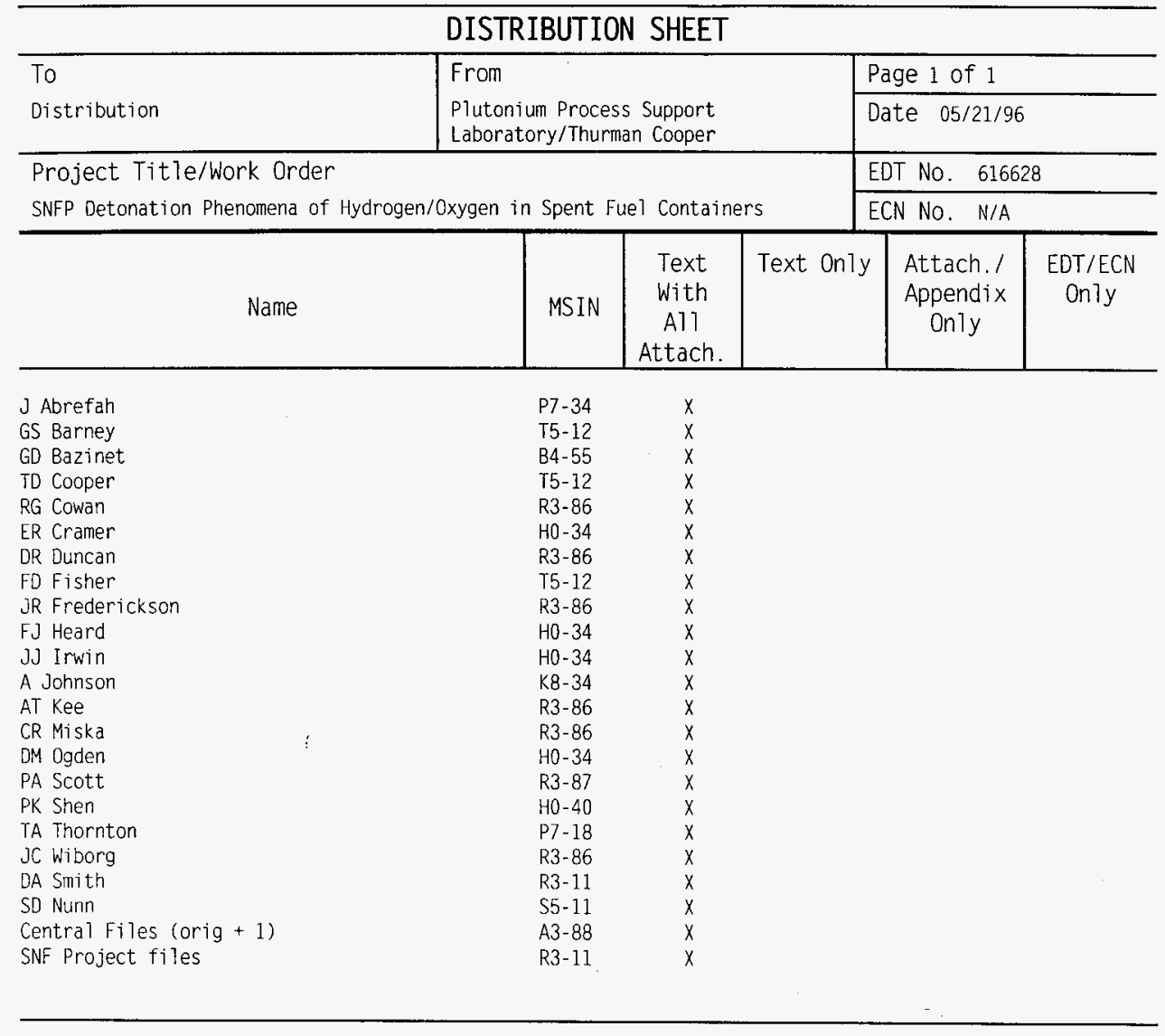

